\title{
Epidemiological aspects and early detection of chronic obstructive airway diseases in the elderly
}

\author{
B. Lundbäck*,\#, A. Gulsvik", M. Albers ${ }^{+}$, P. Bakkeø, E. Rönmark",\$, G. van den Boom ${ }^{+}$, J. Brøgger", \\ L-G. Larsson", I. Welle", C. van Weel ${ }^{+}$, E. Omenaas
}

Epidemiological aspects and early detection of chronic obstructive airway diseases in the elderly. B. Lundbäck, A. Gulsvik, M. Albers, P. Bakke, E. Rönmark, G. van den Boom, J. Brogger, L-G. Larsson, I. Welle, C. van Weel, E. Omenaas. (C) ERS Journals Ltd 2003.

ABSTRACT: The burdens of chronic obstructive airway diseases among the elderly in Europe, and worldwide, are increasing. Although asthma is common in all ages, the main airway disease affecting the elderly is chronic obstructive pulmonary disease (COPD). The aim of this paper is to review the prevalence and incidence of COPD on the basis of population studies. As the prevalence estimates of asthma are probably well known, only the incidence and remission of asthma will be discussed. The underdiagnosis of obstructive airway diseases is huge. A Dutch programme for early detection of obstructive airway disease among the elderly has, thus, been included in the presentation.

A prerequisite for fighting COPD is to acquire data on illnesses and death. COPD has only recently been defined by cut-off points of spirometric outcomes, which is why measures of the prevalence of COPD have been distorted by use of a large number of different diagnostic terms and lung function criteria. The prevalence of clinicallyrelevant COPD has been estimated in several community studies to 4-6\% in adult population samples, with a considerable increase by age, particularly among smokers. The incidence of COPD not only increases heavily with age and smoking, but also occupational exposure to dust, gas and damp. Precise estimates of the incidence of COPD or spirometric airflow limitation are not available.

Demographic changes will result in a further substantial increase of chronic obstructive airway disorders, mainly chronic obstructive pulmonary disease, among the elderly. The increasing burden of chronic obstructive pulmonary disease has to come to the awareness of the public, governments, health authorities, and industry.

Eur Respir J 2003; 21: Suppl. 40, 3s-9s.
*Unit for Lung and Allergy Research, National Institute of Environmental Medicine, Karolinska Institutet, Stockholm, Sweden, ${ }^{\#}$ The Obstructive Lung Disease in Northern Sweden (OLIN) Studies, Dept of Medicine, Sunderby Central Hospital of Norrbotten, Luleå, Sweden, "Dept of Thoracic Medicine, Institute of Medicine, University of Bergen, Bergen, Norway, ${ }^{+}$Dept of General Practice, University Medical Centre, Nijmegen, the Netherlands, ${ }^{8}$ Dept of Respiratory Medicine and Allergy, University of Umeå, Sweden.

Correspondence: B. Lundbäck, Unit for Lung and Allergy Research, National Institute of Environmental Medicine, Karolinska Institutet, SE - 17177 Stockholm, Sweden.

Fax: 468300619

E-mail: bo.lundback@telia.com

Keywords: Asthma

chronic obstructive pulmonary disease epidemiology

spirometry

Received and accepted: April 122002
Chronic obstructive pulmonary disease (COPD) is a common, costly and preventable disease that has great implications for health [1-5]. After the ages of 40-50 yrs, its prevalence increases considerably with increasing age, particularly among smokers; however, the underdiagnosis is great $[6,7]$. The slowly progressive nature of COPD [3] means that the disease usually remains undetected for many years, and most patients are first identified when they present with an exacerbation. By the time COPD is diagnosed, often $\leqslant 50 \%$ of lung function has already been lost and the need for healthcare utilisation is high [8]. Though the incidence of asthma is large in children and teenagers, the prevalence of asthma remains relatively stable and may also increase slightly among the elderly, in whom it is around $5-10 \%$ in most European countries [9]. Both asthma and, in particular, COPD are chronic and common diseases among the elderly, although asthma may remit [10]. The burdens among the elderly from obstructive airway diseases are increasing.

In the last decades, a number of studies have shown an increasing prevalence of obstructive airway diseases worldwide $[9,11,12]$. It is expected that in the near future demographic changes will result in a further substantial increase of chronic obstructive airway disorders. The main part among the elderly is expected to be due to COPD.

Dutch general practice data from the Continuous Morbidity
Registration show that, over time, incidence has remained stable, whereas prevalence has more than doubled [13]. As prevalence follows population demography, a clear increase can be expected for the period 1996-2020, levelling off in the period 2030-2050 [14].

Within the perspective of obstructive airway disease among the elderly, a review of the current discussion of the criteria for diagnosing COPD, the burden of COPD in terms of prevalence, in part incidence, disability and mortality, has been made. Regarding asthma, mainly incidence has been reviewed. As the underdiagnosis of obstructive airway disease is huge, a Dutch programme for the detection of COPD in society is included.

\section{Methodological considerations}

Diagnostic criteria of chronic obstructive pulmonary disease

Because the term COPD is used in a variety of ways, data on prevalence, incidence, mortality and morbidity from COPD must be interpreted with caution. The diagnostic term COPD has not, in contrast to asthma, been widely used and distributed to the public by physicians and other health 
professionals. Asking a general population about a physician's diagnosis of COPD will generate few affirmative answers from those with irreversible airflow limitation. Most patients will answer that they have asthma, chronic bronchitis, emphysema, or the disease is unrecognised [6,7]. A prerequisite for the diagnosis is spirometry, which is still insufficiently used.

The CIBA Guest Symposium in the late 1950s defined generalised obstructive lung disease as a condition with widespread narrowing of the airways, at least on expiration, causing an increased resistance to airflow. They divided the obstructive lung disease into two subgroups: 1) intermittent or reversible obstructive lung disease, or asthma, and 2) irreversible or persistent obstructive lung disease, later labelled as COPD [15].

Several international and national guidelines have recommended diagnostic criteria for COPD. Operative criteria for the cut-off of the forced expiratory volume in one second (FEV1)/forced vital capacity (FVC) or FEV1/vital capacity (VC) ratio may, however, differ between recommendations. The British Thoracic Society (BTS) [3] and the Global Initiative for Obstructive Lung Disease (GOLD) [4] have recommended a simple cut-off point with a FEV1/FVC ratio of $<0.7$, while the European Respiratory Society (ERS) [1] has recommended a $\mathrm{FEV} 1 / \mathrm{VC}$ ratio of $<88 \%$ predicted in males and $<89 \%$ pred in females. The GOLD criteria are easily applicable, but they may cause bias by including too many cases with the elderly and too few with young adults.

The severity of COPD is defined by level of FEV1 in \% pred. The grading of severity varies considerably among the recommendations. The grading of the BTS [3] seems clinically appropriate, with severe COPD as FEV1 levels $<40 \%$ pred, moderate COPD as FEV1 $\geqslant 40<60 \%$ pred, and mild COPD as FEV1 $\geqslant 60<80 \%$ pred. No agreement exists on what prediction equations should be used when standardising for age, sex and body size. The recommended summary equations of the ERS give predicted FEV1 as $300-400 \mathrm{~mL}$ lower than that observed in healthy nonsmoking Europeans [16]. Using these summary equations will, therefore, underestimate the prevalence of COPD in most European populations.

\section{Measures of incidence and remission}

When measuring incidence, two terms are used. Cumulative incidence is the proportion of a population that becomes affected by a disease during a defined time period. When studying diseases with low incidence and remission, the incidence rate for a time period may be approximated with the cumulative incidence for the period. The incidence is usually given as the number of new cases per 1,000 persons at risk per year. Persons at risk are the subjects not having the studied condition at the start of the observation period.

Regarding remission of asthma, with the exception of asthma in children, only a few articles have been published thus far, and only one focusing on the elderly [10]. The definitions of remission and the methods used vary. COPD, with established lung function impairment defined by today's criteria, may, by definition, not remit. Chronic lung disease, formerly defined by symptom criteria (e.g. chronic nonspecific lung disease (CNSLD)), may remit [17].

\section{Disability adjusted life years lost}

Disability adjusted life years (DALYs) have been launched by the World Bank and supported by the World Health Organization (WHO) as a measure of burden of disease.

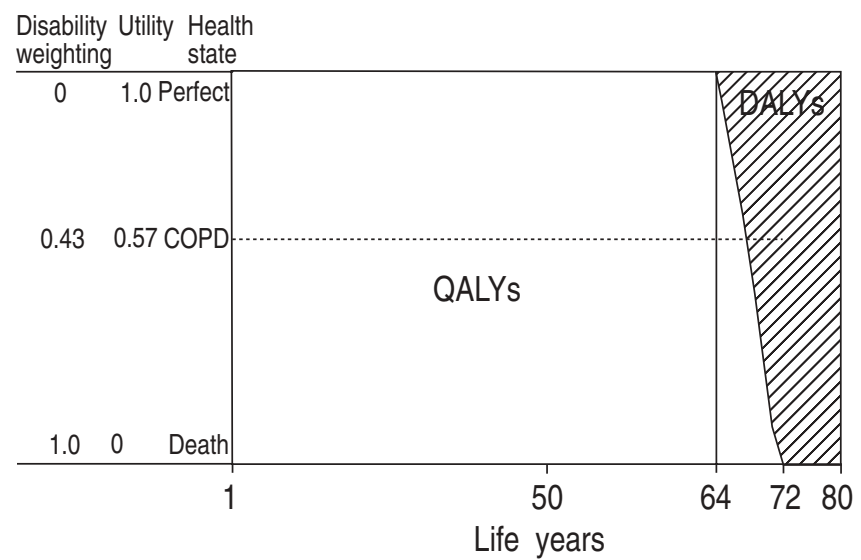

Fig. 1.-Disability adjusted life years lost (DALYs) and years of healthy life lived (QALYs) are complementary concepts. Both approaches multiply the years (x-axis) by the quality of those years (y-axis). DALYs use disability weights to reflect the burden of disease. The average disability weight of severe chronic obstructive pulmonary disease (COPD) is in this example estimated to be 0.43 , the duration of disease to be $8 \mathrm{yrs}$, and the life expectancy to be $80 \mathrm{yrs}$.

Thus, DALYs are the sum of years lost because of premature mortality and years lived with disability, adjusted for the severity of the disability. The disability weight for untreated COPD was estimated to be 0.43 , using a person trial off method [12]. Death is given the disability weight of 1.0 , and complete health the weight of 0.0 (fig. 1). Estimated DALYs for the world are calculated to 29 million DALYs in 1990, of which 2.3 million are in countries that have an established market economy [12].

\section{Burden of chronic obstructive pulmonary disease}

\section{Prevalence of chronic obstructive pulmonary disease}

The prevalence of COPD has been distorted by the use of different diagnostic terms and lung function criteria. Furthermore, a meaningful evaluation of estimates demands knowledge of age distribution and smoking habits in the examined populations.

An Italian general population showed very large differences in prevalence estimates of COPD, when using the 1986 American Thoracic Society (ATS) criteria, the 1995 ERS criteria or "clinical criteria" [18]. For the last $40 \mathrm{yrs}$, the prevalence of COPD has been estimated in community surveys in several Nordic countries [7, 19-23]. Studies from the last two decades indicate that $4-6 \%$ of the adult population suffer from clinically-relevant COPD. Prevalence increases heavily with age, and recent surveys have shown only small differences between males and females.

Prevalence studies in the UK have been reviewed by STRACHAN [24], who stated that only one national study of ventilatory function had been conducted. This study of 5,547 males and females aged 16-65 yrs showed that a FEV1 of $\geqslant 2$ standard deviations (SD) below the age and height predicted value was present in $10 \%$ of the males and $11 \%$ of the females. A Norwegian spirometry survey of a general population sample aged 18-73 yrs found a prevalence of $6 \%$ of airflow limitation, defined as FEV1/FVC $<0.7,12 \%$ had FEV $1<80 \%$ pred using Norwegian reference values [19], and $4.5 \%$ had both the ratio and FEV1 $<80 \%$ pred [21]. Using stages advocated by the BTS [3] only $0.2 \%$ of the adult population could be defined as severe cases of airflow limitation having FEV $1<40 \%$ pred (fig. 2). A spirometry survey in the Po River 

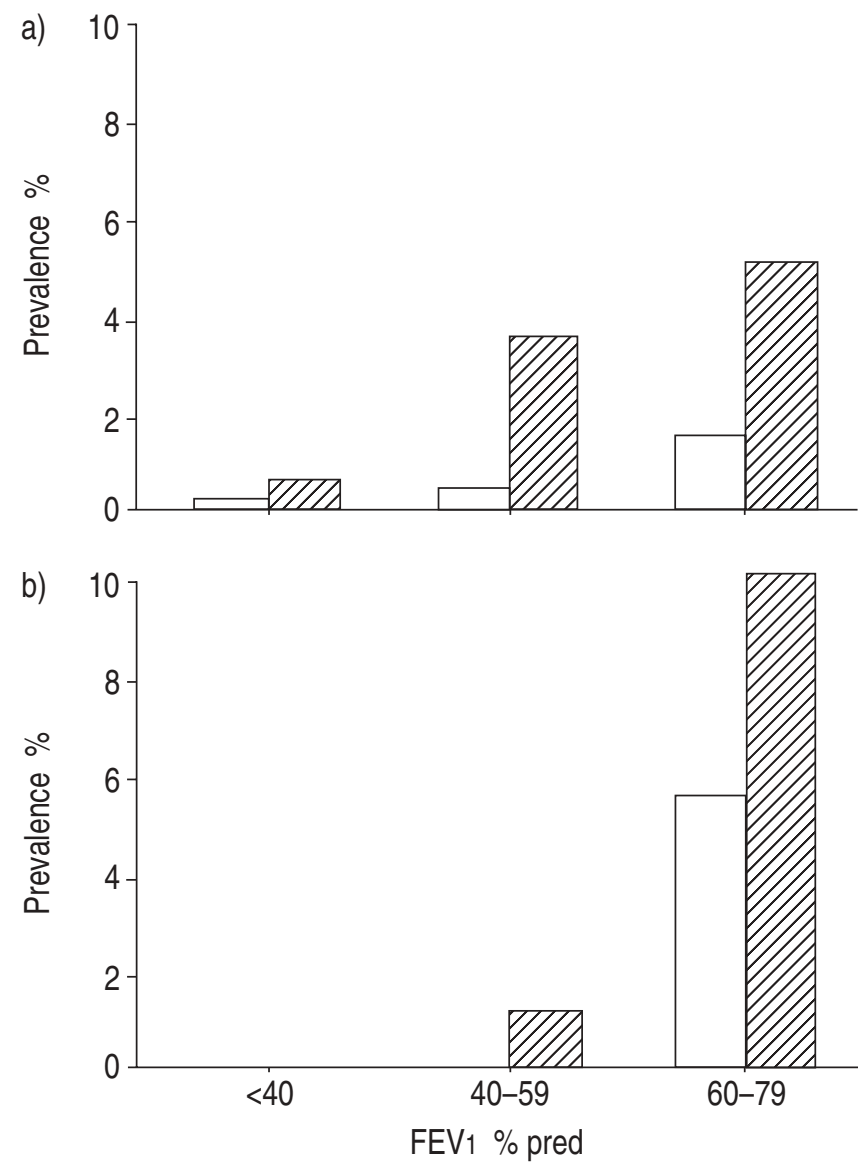

Fig. 2.-Percentage distribution of the prevalence of a) chronic obstructive pulmonary disease (forced expiratory volume in one second (FEV1)/forced vital capacity (FVC) $<0.7$ and $\mathrm{FEV}_{1}>80 \%$ pred) and b) restrictive or other lung function impairment $(\mathrm{FEV} 1 / \mathrm{FVC} \geqslant 0.7$ and $\mathrm{FEV}_{1}<80 \%$ pred) in a general population aged $18-73$ yrs in Bergen, Norway. $\square$ : 18-44 yrs; $\mathbb{Z}$ : 45-73 yrs.

delta area in Italy [18] in a random sample aged 25-73 yrs yielded spirometric prevalence estimates that are similar to those obtained in the Nordic countries. Approximately $0.5 \%$ of the population could be defined as having severe COPD using the cut-off point of FEV $1<50 \%$ pred.

In a study carried out in random population samples aged 40-69 yrs in seven different areas of Spain [25], COPD was defined as FEV1/FVC ratio $<88 \%$ pred in males and $<89 \%$ in females, with a $<12 \%$ increase in FEV1 at bronchodilator test. An overall prevalence of $10.6 \%$ for COPD was observed. In a USA population survey of 16,695 subjects aged $17-89$ yrs in 1988-1994, airflow limitation was defined as in the Norwegian study [21] and in the criteria of the BTS for COPD [3]. The overall prevalence of a low lung function was $6.8 \%$, while $8.5 \%$ reported previous or current diagnosis of obstructive lung disease [26]. Data from the same study indicate that $50 \%$ of smokers may develop COPD [27], similar to recent Swedish data [23].

The third National Health and Nutrition Examination Survey (NHANES III) and other national healthcare surveys in the USA suggest that between 2.4-7.0 million people are actually diagnosed with COPD [27]. However, the National Center for Health Statistics estimates that COPD affects $>16$ million US citizens [28]. The model, which has been developed from the NHANES III to estimate prevalence of COPD from the known smoking status of the population, estimated the cases of COPD to be 1.5 million persons with COPD in Spain, 3.0 million persons in the UK, 2.7 million persons in Germany, 2.6 million persons in Italy, and 2.6 million in France [27].

The Global Burden of Disease Study has estimated the worldwide prevalence of COPD to 834 per 100,000, which yields 44 million cases of COPD [29]. In the regions of countries with established market economies, the prevalence rate was estimated to be as low as 535 per 100,000 . This estimate includes all ages. Since most cases of COPD usually become clinically apparent after the age of $45 \mathrm{yrs}$, the study grossly underestimates the prevalence of the disease in adults and the elderly. These estimates may be too low in countries with a life expectancy of $\geqslant 80$ yrs and with $>20 \%$ daily smokers.

\section{Estimates of incidence of chronic obstructive pulmonary disease}

Precise estimates of incidence of physician-diagnosed COPD or spirometric airflow limitation as defined by modern guidelines, are so far not available. Longitudinal studies of lung function [30-32] have shown that the development of airflow limitation is heavily dependent on smoking habits and dust exposure. In most cases, the decline seems to occur along a slowly accelerating curvilinear path.

A limited number of studies have performed incidence measures of COPD; however, in these measures the cut-off levels of the outcome variable differ largely. A Finnish study [30] of a population aged 40-64 yrs in 1961 was re-examined in 1971. The average annual incidence of a spirometric ratio of $\mathrm{FEV} 1 / \mathrm{FVC}<0.6$ was $0.2 \%$ for the whole population and $1.0 \%$ in smokers. In a $13-y r$ follow-up study, conducted in a population aged 19-70 yrs in Cracow, Poland [33] between 1968-1981, COPD was defined as FEV1 $<65 \%$ pred. The average incidence per year was $0.5 \%$. The incidence was twice as high in males than in females, and a considerable number of new cases of COPD was also seen in never-smokers.

In the Netherlands, the incidence of CNSLD (mainly defined by symptomatic criteria) was studied from 1965-1985 in the Zutphen community population of males aged $40-59$ yrs. The average incidence was estimated at $1.5 \%$ per year [17].

Within the Global Burden of Disease Study [29], estimates were made of incidence of COPD in eight health regions of the world. The estimate for countries with market economies was calculated to be 84 per 100,000 , which is less than one-fifth of that observed for Cracow, Poland [33].

\section{Disability}

Chronic obstructive airway disorders are also a growing cause of disability. In 1990, COPD was the 12th most burdensome condition in the world. According to the projection from the 1990 WHO Global Burden of Disease Study, COPD will rank 5th in 2020, being responsible for $4 \%$ of total DALYs lost [34]. Only ischaemic heart disease, major depression, traffic accidents and cerebrovascular disease will cause a greater burden.

In 1990, the WHO Global Burden of Disease study showed COPD to be the sixth leading cause of death worldwide [34]. By 2020, COPD is expected to rise to the third position, after ischemic heart disease and cardiovascular disease. In 1990 , COPD caused $4 \%$ of deaths ( $>2$ million) worldwide; in 2020 , this figure is projected to rise to $7 \%$ (4-5 million). 


\section{Asthma}

\section{Incidence}

Studies reporting the incidence of asthma among adults show a wide range of results, and vary from $0.4-11 \cdot 1,000$ persons $^{-1}$ under risk per year, indicating that the results are largely dependent on the methods used, including the definitions of incident asthma and the population under risk as well [35]. In contrast to adulthood and old age, the incidence of asthma in childhood is considerably higher and has been estimated at $7-10 \cdot 1,000$ persons $^{-1} \cdot \mathrm{yr}^{-1}$ from 7-10 yrs of age, and the incidence decreases slowly with increasing age [36].

Prospective studies of samples of the general population, although still few, have reported incidence rates of $2-4 \cdot 1,000$ persons ${ }^{-1} \cdot \mathrm{yr}^{-1}\left[37\right.$ ] and $2-8 \cdot 1,000^{-1} \cdot \mathrm{yr}^{-1}$ [38]. Lower incidence rates of $\sim 1 \cdot 1,000^{-1}$ have been found in other studies [39-41]. Register studies generally provide even lower incidence rates. In a Finnish study [42], the incidence was estimated prospectively during a 6-yr period by two repeated questionnaires, and also from a medical register in the same sample. The population study-based measure of incidence was $1.5 \cdot 1,000$ persons $^{-1} \cdot \mathrm{yr}^{-1}$, while the incidence calculated from hospital admissions was one-half of that. Retrospective studies also provide lower incidence rates than prospective studies. Incidence of asthma (or wheeze) measured prospectively in a cohort from birth to age $33 \mathrm{yrs}$ was $13 \cdot 1,000^{-1} \cdot \mathrm{yr}^{-1}$, but recalling asthma or wheeze when interviewed resulted in an incidence of $9 \cdot 1,000^{-1} \cdot \mathrm{yr}^{-1}$ [43]. A recent Swedish retrospective study reported the incidence to be lower in the past, which may reflect an increase of asthma, or an effect of forgetfulness, or both [44]. Adults often forget their childhood asthma.

The incidence of asthma among the elderly has been estimated, not only in the USA, but also among the middleaged and elderly, by longitudinal studies during $10 \mathrm{yrs}$ within the Obstructive Lung Disease in Northern Sweden Studies (OLIN). After exclusion of all subjects with respiratory disease or symptoms common in asthma at the start of the observation period, the incidence of asthma was estimated at $2.3 \cdot 1,000^{-1} \cdot \mathrm{yr}^{-1}$. The incident cases were confirmed by clinical examinations including methacholine tests. Risk factors for incident asthma were a family history of asthma, current and exsmoking, and female sex. Smoking, as a risk factor, behaved differently compared with results from cross-sectional studies in the same cohorts. The incidence of wheezing and of new users of asthma medicines was both $11 \cdot 1,000$ person$\mathrm{s}^{-1} \cdot \mathrm{yr}^{-1}$, indicating that the incidence of asthma may have been underestimated [35].

\section{Remission}

Approximately one-half of the asthmatic children may outgrow their asthma before adulthood; however, asthma may recur later in life. Only a few studies that allow conclusions about the general population have focused on remission of asthma in adults. The criteria for remission have varied. A study in Tucson, AZ, USA, found remission of asthma to be $22 \%$ during 9 yrs. The remission rate was highest $(65 \%)$ in subjects aged $10-19$ yrs [45]. In a 25-yr follow-up study in the Netherlands, different outcomes of remission of asthma in asthmatics aged 13-44 yrs at baseline were measured. After $25 \mathrm{yrs}, 21 \%$ did not have bronchial hyperresponsiveness (BHR), while $11 \%$ were in remission if normal lung function and freedom from symptoms also were required [46]. The remission of asthma in a population-based

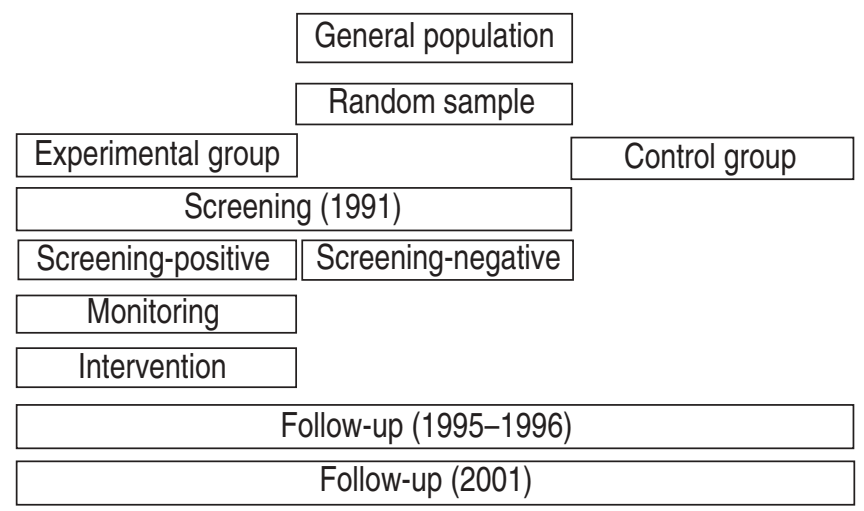

Fig. 3. - The Dutch Detection, Intervention and Monitoring of COPD and Asthma in family practice (DIMCA) study design.

asthma cohort of the middle-aged and elderly within the Swedish OLIN studies was found to be $6 \%$ during 10 yrs. Remission was defined as no symptoms without using asthma medicine [10].

\section{Screening of obstructive airway disease: the Dutch DIMCA study}

In 1990, it was hypothesised that the maximum benefit of inhaled corticosteroids (ICS) treatment, such as moderating the course of lung function decline, could be expected if treatment was instituted as early as possible in the development of the disease. This concept resulted in the establishment of the Dutch Detection, Intervention and Monitoring of COPD and Asthma in family practice (DIMCA) project in Nijmegen in 1991 (fig. 3) [47]. The study was designed to be representative for the Dutch general population. Because of the specific nature of the Dutch healthcare system, virtually all Dutch citizens are automatically registered at a general practice and receive ongoing care. In the DIMCA study, a random sample was selected from a screening of a $10 \%$ sample of the population and recruited for the trial if persistent signs and/or symptoms could be demonstrated over time. The subjects were taken from the practice lists of 10 general practices in the eastern area of the Netherlands. The sample was divided into an intervention and a control group.

The study had two objectives: 1) to assess the efficacy of ICS treatment of early obstructive airway disease; and 2) to assess the effectiveness of early case-finding and early treatment.

Subjects in the general population aged 25-70 yrs with

Table 1.-Screening procedure in the Dutch Detection, Intervention and Monitoring of COPD and Asthma in family practice (DIMCA) study

"Screening-positive"

If yes to one of the following:

Severe COPD or asthma-related symptoms

Bronchial obstruction (FEV1/VC $\leqslant$ pred value minus $1.64 \mathrm{SD}$ )

FEV1 reversibility $\geqslant 15 \%$ pred at 15 min after administration of $800 \mu \mathrm{g}$ salbutamol

If yes to two of the following:

FEV1/VC $\leqslant$ pred value minus $1 \mathrm{SD}$

FEV1 reversibility $\geqslant 10 \%$ pred at 15 min after administration of $800 \mu \mathrm{g}$ salbutamol

Mild asthma or COPD-related symptoms

COPD: chronic obstructive pulmonary disease; FEV1: forced expiratory volume in one second; VC: vital capacity; pred: predicted. 
Table 2. - Detection procedure in a 2-yr monitoring programme in the Dutch Detection, Intervention and Monitoring of COPD and Asthma in family practice (DIMCA) study

\begin{tabular}{|c|c|}
\hline Group & Criteria \\
\hline $\begin{array}{l}\text { 1st group: subjects with persistently reduced lung } \\
\text { function or increased } \mathrm{BHR}^{\#}\end{array}$ & $\begin{array}{l}\text { Two out of four measurements during the first } 6 \text { months: } \\
\text { FEV } 1 \leqslant \text { FEV } 1 \text { pred minus } 2 \mathrm{SD} \text {, and/or PC } 20<2 \mathrm{mg} \text { histamine } \cdot \mathrm{mL}^{-1} \\
\text { and FEV1-reversibility } \geqslant 15 \%\end{array}$ \\
\hline $\begin{array}{l}\text { 2nd group: subjects with a rapid decline of lung } \\
\text { function with signs of BHR }\end{array}$ & $\begin{array}{l}\text { A decline in FEV1 }>80 \mathrm{~mL} \cdot \mathrm{yr}^{-1} \text { in } 1 \mathrm{yr} \text { of monitoring, and a } \\
\mathrm{PC} 20 \leqslant 8 \mathrm{mg} \text { histamine } \cdot \mathrm{mL}^{-1} \text {, and/or FEV1-reversibility } \geqslant 10 \%\end{array}$ \\
\hline $\begin{array}{l}\text { 3rd group: subjects with a moderate increase in the decline } \\
\text { in lung function or signs of BHR }\end{array}$ & $\begin{array}{l}\text { A decline in FEV } 1 \text { between } 40-80 \mathrm{~mL} \cdot \mathrm{yr}^{-1} \text { during } 2 \mathrm{yrs} \text { of monitoring, } \\
\text { and a chronic productive cough for at least } 3 \mathrm{months} \cdot \mathrm{yr}^{-1} \text {, and/or } \\
\text { at least one exacerbation } \cdot \mathrm{yr}^{-1}\end{array}$ \\
\hline
\end{tabular}

FEV1: forced expiratory volume in one second; PC20: provocative concentration causing a 20\% fall in FEV1; pred: predicted; BHR: bronchial hyperresponsiveness. ${ }^{\#}$ : Once identified, these subjects were withdrawn from monitoring; ${ }^{\uparrow}$ : in these groups ethical considerations prompted intervention.

signs of COPD or asthma at an early stage were detected. This was done by a two-stage protocol involving screening and a subsequent 2-yr monitoring of all subjects with positive results in the screening. Subjects were excluded from screening in case of diagnosed asthma or COPD, other lung diseases, congestive heart failure, serious morbidity (life expectancy $<4$ yrs), a severe physical or mental handicap, or corticosteroid dependency (inhaled or oral). A total number of 1,749 subjects met the inclusion criteria, and 1,155 subjects $(66 \%)$ agreed to participate in the screening. Screening consisted of lung function testing and assessment of current symptoms.

Measurement included assessment of symptoms, exacerbations, smoking behaviour, health-related quality of life, functional status, allergy, lung function, reversibility, BHR, work disability and healthcare cost. At the 10-yr follow-up in 2001, two independent clinicians allocated all subjects as: 1) evidently developed asthma or COPD; 2) at risk of developing such a disorder; or 3) not at risk for development of asthma or COPD.

The screening procedure is described in table 1 . The study covers the whole range, from detection of formerly undiagnosed, monitoring the natural course of the early stage of disease, and early treatment of subjects that are considered to be "at risk", towards identification of prognostic factors for the development of COPD or asthma.

Symptoms or signs of obstructive airway disease during the screening ("positive") were found in 604 subjects $(52 \%)$. Of these, 384 subjects $(64 \%)$ agreed to participate in a $2-y r$ monitoring programme, consisting of periodical lung function measurements and assessment of symptoms and exacerbations.

During this stage (table 2), three mutually exclusive groups were distinguished. The first consisted of subjects with persistently reduced lung function or increased BHR. Once identified, these subjects were withdrawn from monitoring. Subjects with a rapid decline of lung function with signs of BHR were assigned to the second group. In these groups, ethical considerations prompted intervention. Subjects with a moderate increase in the decline in lung function or signs of BHR were assigned to the third group. Subjects who completed the two stages of the detection programme, but did not meet the aforementioned criteria were regarded as "healthy".

During the monitoring, 252 subjects were detected with signs of obstructive airway disease at an early stage. Although early airway obstruction could be identified, a final diagnosis of either asthma or COPD was often not possible. As no evidence of biased recruitment or selection was found, the proportion of subjects with signs of airway obstruction at an early stage could, therefore, be extrapolated in the general population [47]. It was concluded that $7.7 \%$ of the general population showed a persistently reduced lung function or increased BHR, another $12.5 \%$ showed a rapid decline in lung function $\left(>80 \mathrm{~mL} \cdot \mathrm{yr}^{-1}\right)$ in combination with BHR, and a further $19.4 \%$ of the general population showed mild objective signs of obstructive airway disease.

The two-stage detection programme [47] revealed that a large proportion of the general undiagnosed population showed symptoms and objective signs of obstructive airway disease. As found by others [19], $50 \%$ of the general population had respiratory symptoms or signs of obstructive airway disease at the screening. The monitoring stage of the programme further showed that in $\sim 20 \%$ of this general population, a persistently decreased lung function or a rapid decline in lung function was observed, and in these subjects, treatment should be considered [48, 49].

Subjects, although experiencing respiratory complaints, only consult their general practitioner when the quality of their everyday life becomes affected, or when they experience variability in lung function [50]. The large number of undetected and untreated subjects raises the question of practice casefinding or screening. However, potential health gains of screening should be set against the costs inflicted and the potential negative effects, including medicalisation with overconsumption of medical facilities. Furthermore, the over-reliance on medical intervention is a potential adverse effect of screening.

\section{Conclusions}

The burdens among the elderly from obstructive airway diseases, particularly chronic obstructive pulmonary disease, are increasing. Considerable underdiagnosis exists. The public, governments, health authorities, and industry must become aware of the increased burden of chronic obstructive pulmonary disease, the only leading cause of death that is increasing in prevalence worldwide. Health professionals should implement strategies for early detection, effective prevention, diagnosis and treatment of the disabling and life-threatening obstructive airway diseases, like the Dutch Detection, Intervention and Monitoring of Chronic obstructive pulmonary disease and Asthma in family practice (DIMCA) study whose follow-up has been started in 2001 .

\section{References}

1. Siafakas NM, Vermeire P, Pride NB, Paoletti P, Gibson J, Howard P. Optimal assessment and management of chronic obstructive pulmonary disease (COPD). Eur Respir J 1995; 8: 1398-1420.

2. American Thoracic Society. Standards for the diagnosis 
and care of patients with chronic obstructive pulmonary disease. Am J Respir Crit Care Med 1995; 152: Suppl. 5, S77-S120.

3. British Thoracic Society. British Thoracic Society guidelines for the management of chronic obstructive pulmonary disease. Thoracic 1997; 52: Suppl. 5, S1-S28.

4. Pauwels RA, Buist AS, Ma P, Jenkins CR, Hurd SS. Global strategy for the diagnosis, management, and prevention of chronic obstructive pulmonary disease: National Heart, Lung, and Blood Institute and World Health Organization Global Initiative for Chronic Obstructive Lung Disease (GOLD): executive summary. Am J Respir Crit Care Med 2001; 46: 798-825.

5. Jones PW, Quirk FH, Baveystock CM. The St George's respiratory questionnaire. Respir Med 1991; 85: Suppl. B, 25-31.

6. Tirimanna PR, van Schayck CP, den Otter JJ, et al. Prevalence of asthma and COPD in general practice in 1992: has it changed since 1977? Br J Gen Pract 1996; 46: 277-281.

7. Lindström M, Jönsson E, Larsson K, Lundbäck B. Underdiagnosis of chronic obstructive pulmonary disease in Northern Sweden. Int J Tuberc Lung Dis 2002; 6: 76-84.

8. Engström CP, Persson LO, Larson S, Sullivan M. Healthrelated quality of life in COPD: Why both disease-specific and generic measures should be used. Eur Respir J 2001; 18: 69-76.

9. Lundbäck B. Epidemiology of rhinitis and asthma. Clin Exp Allergy 1998; 28: Suppl. 2, 3-10.

10. Rönmark E, Jönsson E, Lundbäck B. Remission of asthma in the middle aged and elderly: report from the Obstructive Lung Disease in Northern Sweden study. Thorax 1999; 54: 611-613.

11. Weiss KB. An Overview of recent trends in asthma epidemiology. Eur Respir Rev 1996; 6: 35, 101-104.

12. Murray CJL, Lopez AD, eds. The Global Burden of Disease. A comprehensive assessment of mortality and disability from diseases, injuries and risk factors in 1990 and projected to 2020. Publication from the Harvard School of Public Health on behalf of The World Health Organization and the World Bank. Cambridge, MA, Harvard University Press, 1996.

13. Van Weel C, Smith H, Beasley JW. Family practice research networks. Experience from three countries. J Fam Pract 2000; 49: 938-943.

14. Van Weel C. Ethics of health care for the elderly. Longevity, aging and the demand of primary care. In: Butler RN, Jasmin C, eds. Longevity and Quality of Life. Opportunities and Challenges. New York, Kluwer/Plenum, 2000.

15. Fletcher CM, Gilson JH, Hugh-Jones P, Schadding JG. Terminology, definitions and classification of chronic pulmonary emphysema and related conditions. A report of the conclusions of the CIBA guest symposium. Thorax 1959; 14: 286-299.

16. Roca J, Burgos F, Sunyer J, et al. Reference values for forced spirometry. Eur Respir J 1998; 11: 1354-1362.

17. Heederik D, Kromhout H, Kromhout D, Burema J, Bierstecker K. Relationship between occupational smoking, lung function, and incidence and mortality of chronic nonspecific lung disease: The Zutphen study. Br J Ind Med 1992; 49: 299-308.

18. Viegi G, Pedreschi M, Pistelli F, et al. Prevalence of airways obstruction in a general population. European Respiratory Society vs American Thoracic Society definition. Chest 2000; 117: Suppl. 2, 339S-345S.

19. Gulsvik A. Prevalence and manifestations of obstructive lung disease in the city of Oslo. Scand J Resp Dis 1979; 60: 286-296.

20. Lange $\mathrm{P}$, Groth S, Nyboe J, et al. Chronic obstructive lung disease in Copenhagen: cross-sectional epidemiological aspects. J Intern Med 1989; 226: 25-32.

21. Bakke PS, Baste V, Hanoa R, Gulsvik A. Prevalence of obstructive lung disease in a general population: relation to occupational title and exposure to some airborne agents. Thorax 1991; 46: 863-870.

22. Isoaho R, Puolijoka H, Huhti E, Kivela SL, Laippala P, Tala E. Prevalence of chronic obstructive pulmonary disease in elderly Finns. Respir Med 1994; 88: 571-580.

23. Lundbäck B, Lindberg A, Lindström M, et al. Not 15 but $50 \%$ of smokers develop COPD? - Report from the Obstructive Lung Disease in Northern Sweden Studies. Respir Med 2003; 97: 115-122.

24. Strachan D. Epidemiology: A British perspective. In: Calverly P, Pride N, eds. Chronic Obstructive Pulmonary Disease. London, Chapman \& Hall, 1995; pp. 47-67.

25. Sobradillo V, Miravitles M, Jiménez CA, et al. Epidemiological study in chronic obstructive pulmonary disease in Spain (IBERPOC): prevalence of chronic respiratory symptoms and airflow limitation. Arch Broncopneumol 1999; 35: 159-166.

26. Mannino DM, Gagnon RC, Petty TL, Lydick E. Obstructive lung disease and low lung function in adults in the United States. Data from the National Health and Nutrition Examination Survey, 1988-1994. Arch Intern Med 2000; 160: 1683-1689.

27. Stang P, Lydick E, Silberman C, Kempel A, Keating ET. The prevalence of COPD: Using smoking rates to estimate disease frequency in the general population. Chest 2000; 117: Suppl. 2, 354S-359S.

28. National Center for Health Statistics. Vital and Health Statistics. Series 10, No. 199. Washington, DC, Government Printing Office, 1998.

29. Murray CJL, Lopez AD, eds. Global Health Statistics. A compendium of incidence, prevalence and mortality estimates for over 200 conditions. Publication from the Harvard School of Public Health on behalf of the World Health Organization and the World Bank. Cambridge, MA, Harvard University Press, 1996.

30. Huhti E, Ikkala J. A follow-up study on respiratory symptoms and ventilatory function in a middle-ages rural population. Eur J Respir Dis 1980; 61: 33-45.

31. Humerfelt S, Gulsvik A, Skjærven R, et al. Decline in FEV1 and airflow limitation related to occupational exposures in men of an urban community. Eur Respir J 1993; 6: 10951103.

32. Heederik D, Kromhout H, Burema J, Bieerstecker K, Kromhout D. Occupational exposure and 25 years incidence rate of non-specific lung disease - the Zutphen study. Int $J$ Epidemiol 1990; 19: 945-952.

33. Krzyzanowski M, Jedrychowski W, Wysocki M. Factors associated with the change in ventilatory function and the development of chronic obstructive pulmonary disease in a 13-year follow up of the Cracow study. Am Rev Respir Dis 1986; 134: 1011-1019.

34. Murray CJL, AD Lopez. Alternative visions of the future: projecting mortality and disability, 1990-2020. In: Murray CJL, AD Lopez, eds. The Global Burden of Disease. A comprehensive assessment of mortality and disability from diseases, injuries and risk factors in 1990 and projected to 2020. Publication from the Harvard School of Public Health, on behalf of the World Health Organization and the World Bank. Cambridge, MA, Harvard University Press, 1996; pp. 361-395.

35. Lundbäck B, Rönmark E, Jönsson E, Larsson K, Sandström $\mathrm{T}$. Incidence of physician-diagnosed asthma in adults - a real incidence or a result of increased awareness? Report from the Obstructive Lung Disease in Northern Sweden Studies. Respir Med 2001; 95: 685-692.

36. Rönmark E, Jönsson E, Platts-Mills T, Lundbäck B. Incidence and remission of asthma in school children report from the Obstructive Lung Disease in Northern Sweden. Pediatrics 2001; 107: e37.

37. Broder I, Higgins MW, Mathews KP, Keller JB. Epidemiology of asthma and allergic rhinitis in a total community, 
Tecumseh, Michigan. J Allergy Clin Immunol 1974; 54: 100110.

38. Dodge R, Burrows B. The prevalence and incidence of asthma and asthma-like symptoms in a general population sample. Am Rev Respir Dis 1980; 122: 567-575.

39. Troisi RJ, Speizer FE, Rosner B, Trichopoulus D, Willett WC. Cigarette smoking and incidence of chronic bronchitis and asthma in women. Chest 1995; 108: 1557-1561.

40. McWhorter WP, Polis MA, Kaslow RA. Occurrence, predictors, and consequences of adult asthma in NHANESI and follow-up survey. Am Rev Respir Dis 1989; 139: 721-724.

41. Schachter EN, Doyle CA, Beck GJ. A prospective study of asthma in a rural community. Chest 1984; 85: 623-630.

42. Vesterinen E, Kaprio J, Koskenvou M. Prospective study of asthma in relation to smoking habits among 14,729 adults. Thorax 1988; 43: 534-539.

43. Strachan DP, Butland BK, Anderson HR. Incidence and prognosis of asthma and wheezing illness from early childhood to age 33 in a national British cohort. BMJ 1996; 312: 1195-1199.

44. Toren $\mathrm{K}$, Hermansson BA. Incidence rate of adult-onset asthma in relation to age, sex, atopy and smoking. A Swedish population-based study of 15,813 adults. Int J Tuberc Lung Dis 1999; 3: 192-197.
45. Bronniman S, Burrows B. A prospective study of the natural history of asthma. Remission and relapse rates. Chest 1986; 90: $480-484$

46. Panhuysen CIM, Vonk JM, Koeter GH, et al. Adult patients may outgrow their asthma. A 25-year follow-up study. Am J Respir Crit Care Med 1997; 1551: 1267-1272.

47. Van den Boom G, van Schayck CP, Rutten-van Molken MP, et al. Active detection of chronic obstructive pulmonary disease and asthma in the general population, Results and economic consequences of the DIMCA program. Am J Respir Crit Care Med 1998; 158: 1730-1738.

48. Haahtela $\mathrm{T}$, Jarvinen M, Kava $\mathrm{T}$, et al. Comparison of a beta-2-agonist, terbutaline, with an inhaled corticosteroid, budesonide, in newly detected asthma. N Engl J Med 1991; 325: 388-392.

49. Dompeling E, van Schayck CP, van Grunsven PM, et al. Slowing the deterioration of asthma and chronic obstructive pulmonary disease observed during bronchodilator therapy by adding inhaled corticosteroids. A 4-year prospective study. Ann Intern Med 1993; 118: 770-778.

50. Van den Boom G, Tirimanna PRS, Kaptein AA, et al. Underpresentation of shortness of breath in the general population: Results of the DIMCA programme. Asthma in Gen Pract 1999; 7: 3-7. 